\title{
Neurosurgical disease encountered in a psychiatric service
}

\author{
S. E. WILliAMS, D. S. BELL, AND R. S. GYE \\ From the Psychiatric Research Unit, Rozelle, N.S.W., Australia
}

SUMMARY One hundred and seven patients with neurosurgical disease treated in a combined neurosurgical, neurological, and psychiatric unit within a psychiatric service were reviewed retrospectively. Most patients had acute confusional states or dementia without gross localizing signs and $\vec{\circ}$ in only three cases did the neurosurgical illness closely resemble a non-organic psychiatric syndrome. The great majority showed abnormalities on physical examination and simple investigations. A past $\vec{\omega}$ history of alcoholism and/or other psychiatric illness was common. Many apparently had been referred to psychiatric hospitals simply because they presented problems of management. Consequently, the staff of the psychiatric hospitals must be aware of neurosurgical disease and have free $\dot{\omega}_{y}$ access to facilities for its investigation and management. If these requirements are fulfilled, the referral of patients with acute confusional states and dementia to psychiatric hospitals may indeed be preferable to their management in general hospitals, where their disturbed behaviour presents variety of problems with which these hospitals are not usually equipped to cope.

Patients with organic brain disease in psychiatric hospitals pose special difficulties in diagnosis, partly because facilities for investigation are required which are seldom available in those hospitals. The recognition of organic brain disease which may be amenable to neurosurgical treatment is particularly important and in this series 'neurosurgical illness' is defined as that illness which would reasonably come under the care of a neurosurgeon at some stage.

Estimates of the incidence of neurosurgical illness in psychiatric hospitals vary widely. Hobbs (1963) found that $0.07 \%$ of patients admitted to an 'open psychoneurotic' ward and $6.30 \%$ to a 'mental hospital' had intracranial tumours. Others have found the incidence of intracranial tumours to range from $0.05 \%$ (Olin and Weisman, 1964) to $0.20 \%$ (Rubert and Remington, 1963), the incidence of subdural haematomas in a neuropsychiatric hospital to be $0.18 \%$ (Pihkanen and Vauhkonen, 1967), and the incidence of the full range of neurosurgical disease in a mental observation unit to be $0.5 \%$ (Gooddy et al., 1960).

The highest incidence of brain tumours based on postmortem studies was established by
Larson (1940) as $13.5 \%$. This figure is ofte quoted despite the fact that small meningiomas. choroid plexus tumours, and the now rare tuberculomas and syphilitic gummas were ? included. On the other hand, Klotz (1957) established an incidence of $2.0 \%$ at postmortem examination, which is similar to the incidence of $2.3 \%$ found in a postmortem study conducted in a general hospital and quoted by Patton and Sheppard (1956). In another study evidence of subdural haematomas, particularly significant in psychiatric hospital practice, was found in $8 \%$ of psychiatric inpatients coming to postmortem examination (Allen et al., 1940), the haematoma being the cause of death in $1.1 \%$.

Intracranial disease, particularly when associated with few or slight physical signs, can result in the admission of neurosurgical patients to psychiatric services. In a group of such patients, this paper explores the clinical presentations, the pathology, and some of the problems of their diagnosis and care.

\section{METHODS}

The records of patients with neurosurgical illness 
TABLE 1

DIAGNOSIS AND DETAILS OR REFERRAL

\begin{tabular}{cccc}
\hline Diagnostic group & $(A)$ & $(B)$ & $(C)$ \\
Admission & Psychiatric & Other \\
primarily & inpatients \\
due to & referrals \\
neurosurgical & intercurrent \\
disorder & $\begin{array}{c}\text { neurosurgical } \\
\text { disorder }\end{array}$
\end{tabular}

\begin{tabular}{|c|c|c|c|c|}
\hline \multicolumn{5}{|l|}{ Tumours } \\
\hline Glioma & 22 & & 2 & 24 \\
\hline Meningioma & & & 1 & 1 \\
\hline Angioma & 1 & & & 1 \\
\hline Ependymoma & & 1 & & 1 \\
\hline Pituitary tumours & 2 & & & 2 \\
\hline Sarcoma & 2 & & & 2 \\
\hline \multicolumn{5}{|l|}{ Secondaries and } \\
\hline reticulosis & 11 & 1 & 1 & 13 \\
\hline Subdural haematoma & 12 & 2 & 3 & 17 \\
\hline \multicolumn{5}{|l|}{ Subdural hygroma } \\
\hline Arachnoid cyst & 1 & & 1 & 2 \\
\hline Closed head injury & 7 & 8 & 2 & 17 \\
\hline \multicolumn{5}{|l|}{ Subarachnoid haemor- } \\
\hline rhage & 7 & 1 & & 8 \\
\hline Aneurysm & 2 & & & 2 \\
\hline \multicolumn{5}{|l|}{ Hydrocephalus - } \\
\hline \multicolumn{5}{|l|}{ Occult, secondary to } \\
\hline $\begin{array}{l}\text { cryptococcus and } \\
\text { congenital }\end{array}$ & 7 & 1 & 3 & 11 \\
\hline Encephalitis & 1 & 1 & & 2 \\
\hline \multirow{5}{*}{$\begin{array}{l}\text { Benign intracranial } \\
\text { hypertension } \\
\text { Spinal meningioma and } \\
\text { spinal degenerative } \\
\text { disease } \\
\text { Cerebral abscess }\end{array}$} & & & & \\
\hline & 1 & & & 1 \\
\hline & & & & \\
\hline & 1 & 1 & & 2 \\
\hline & & 1 & & 1 \\
\hline Totals & 77 & 17 & 13 & 107 \\
\hline
\end{tabular}

admitted during a four year period (1966-69) to the Psychiatric Research Unit (PRU) were reviewed. The PRU provides a neurological and neurosurgical service to psychiatric hospitals in New South Wales.

Table 1 records the diagnoses and referral details of the 107 patients in the series. Of the 77 referred from psychiatric sources, 73 were transferred from psychiatric hospitals and four were referred by psychiatrists in private practice. In 17 others (column B) the neurosurgical illness was clearly intercurrent with a psychiatric disorder, often in long-stay inpatients. A further 13 (column C) were referred direct to the PRU from non-psychiatric sources such as general hospitals, general practitioners, and neurologists and in most of these psychiatric illness was assumed by the referring source, either complicating management or presenting diagnostic difficulties.

Of the 77 patients referred from psychiatric hospitals, 46 had been admitted under legal compulsion; of these 35 had been described as being 'unable to care for themselves' and/or 'not under proper care and control', eight as 'dangerous to others', and six as 'suicidal'. A definite diagnosis of organic disease was made at the time of admission to a psychiatric hospital in 44 of these $77(60 \%)$, and in a further $15(21 \%)$ the possibility of organic disease was recognized. The psychiatric diagnoses made on admission were: depressive reaction (nine cases), schizophrenia (three), paranoid and unspecified psychosis (four), personality disorder and/or alcoholism (11), and dissociative reaction (one). Of course, many of these patients, especially those with alcoholism, did in fact have a psychiatric disturbance in addition to their neurosurgical disease and in these cases two diagnoses were often justified.

DELAY IN DIAGNOSIS The interval between admission to the psychiatric hospital and subsequent referral to the PRU may be taken as a measure of the delay in diagnosis (applicable only to cases in column A, Table 1). In the case of 'acute' lesions (subarachnoid haemorrhage, subdural haematoma, head injury) this interval ranged from a few hours to 22 days

TABLE 2

CLINICAL ABNORMALITIES (109) AND SPECIAL INVESTIGATIONS

\begin{tabular}{lcc}
\hline \multirow{2}{*}{$\begin{array}{l}\text { Clinical abnormality found } \\
\text { on referral to PRU }\end{array}$} & \multicolumn{2}{c}{ Abnormality } \\
\cline { 2 - 3 } & $($ no. $)$ & $(\%)$ \\
\hline Psychiatric & & \\
Personality change & 28 & 36 \\
Dementia & 37 & 34 \\
Acute confusional state & 53 & 50 \\
Delusions, hallucinations & 21 & 20 \\
Depression & 12 & 10 \\
Other psychiatric abnormality* & 26 & 24 \\
Alcoholism or previous psychiatric illness & 47 & 43 \\
& & \\
Neurological & 37 & 35 \\
Headache \pm vomiting & 21 & 20 \\
Papilloedema & 22 & 21 \\
Meningeal irritation & 23 & 22 \\
Epilepsy & 18 & 17 \\
History or evidence of head injury & 34 & 33 \\
Ataxia & 36 & 34 \\
Unilateral weakness or pyramidal signs & 17 & 16 \\
Dysphasia & 19 & 18 \\
Visual field defects & 24 & 22 \\
Other cranial nerve abnormalities & 22 & 21 \\
Other signs $\dagger$ & & \\
Investigations & & \\
Chest $x$-ray & & \\
Skull $x$-ray & & 6 \\
EEG & 33 & 68 \\
Lumbar puncture and CSF & 32 & 30 \\
Cerebral scan & 10 & 9 \\
& & 72 \\
\hline 'Ontrast radiology & & \\
\hline
\end{tabular}

* 'Other psychiatric abnormality' includes aggressive behaviour, anxiety, inability to cope, emotional lability, and social deterioration. †'Other neurological signs' includes parietal lobe signs, increased jaw jerk, snout reflex. 
(mean five days, median three days). For the slowly progressive lesions (tumour, hydrocephalus) the range was from some hours to five years nine months (mean 148 days, median 14 days), In eight cases the interval was longer than three months and in 10 the recognition of organic diseases seems to have been unduly delayed, but no single feature distinguishes these cases or provides an adequate explanation for the delay.

CLINICAL FEATURES Clinical abnormalities found on admission to the PRU and the results of special investigations of all patients in the series are summarized in Table 2. This displays the clinical profile of patients with neurosurgical illness presenting through a psychiatric service. The terms 'confusional state' and 'dementia' are used in the sense defined by Victor and Adams (1966) and are viewed as purely clinical pictures rather than diagnostic entities.

At the time of referral to the PRU, 66 of the 77 patients referred from psychiatric services displayed either a confusional state or dementia. The other common feature, which was characteristic of the series as a whole, was personality change, in most cases associated with dementia. Of the 11 remaining patients without dementia or confusional state, dysphasia formed a prominent feature in three, emotional lability in two, and frontal lobe syndrome with hypomanic features in one. Headache and depression were present in two, persistent headache after recovery from head injury in one, focal seizures which were thought to be hysterical in another, and in the remaining patient a paranoid psychosis in association with paraplegia due to a spinal meningioma.

\section{DISCUSSION}

The common presenting features of organic intracranial disease in this series were confusional states and dementia, without gross localizing neurological signs. As might be expected, most cases of personality change were associated with dementia. Although hallucinations and delusions were common, presentations closely resembling 'functional' psychiatric disease were rare. These findings are in accord with those of Bleuler (1951), who reviewed a series of 600 cases of brain tumour and found that $83 \%$ showed either an acute confusional state or dementia. $\mathrm{He}$ noted that the literature does not present a balanced view because it emphasizes the rare, exceptional, and puzzling psychopathological pictures.
In only a few cases did psychiatric 'syndromes' appear to correlate with lesions in specific areas. Hypomania and frontal lobe syn- 0 drome due to a subfrontal craniopharyngioma ${ }_{0}$ was found in one patient (Dinnen et al., 1969) and two patients in whom a prominent feature was inappropriate laughter had lesions involving the pons. Two patients with tumours of the third $\vec{\Rightarrow}$ ventricle had outbursts of angry and aggressive behaviour.

REASONS FOR ADMISSION If the most common

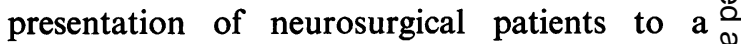
psychiatric service is an 'organic brain syn- $\omega$ drome', why then are they referred to psychiatric rather than general hospitals? Victor and Adams (1966), describing acute confusional states, suggested that:

'The physician has to cope with the problems of diagnosis without the aid of a lucid history, and his. programme of treatment may constantly be threart. ened by the agitation, sleeplessness, and uncoopere $\vec{N}$ tive attitude of the patient. The nursing personnel is 0 often sorely taxed by the necessity of providing satisfactory environment for the convalescence of $c$ the patient, and, at the same time, of maintaining a tranquil atmosphere for the other patients in the ward. And the family is appalled by the sudden spectre of insanity and all that it entails. In such circunt $\vec{\varphi}$ stances it is a great temptation to rid oneself of the clinical problem by transferring the patient to a psychiatric hospital'.

That many of the patients in our series were management problems is confirmed by the high proportion of involuntary admissions. Briscoe $\stackrel{\mathbb{Q}}{\square}$ (1968), in a study of 100 patients admitted under $\overrightarrow{\vec{O}}$ legal compulsion to an admission centre, believed that 50 of them were chiefly problems of emergency disposal. In this context a history of alcoholism and previous psychiatric illness would seem to increase the likelihood of referral to a psychiatric hospital. Indeed, in 19 cases in this series, patients with an established diagnosis of organic disease were referred to psychiatric hospitals, clearly on the assumption that psychi- 0 atric hospitals are better suited to manage patients who are difficult and uncooperative whether physically ill or not.

DIAGNOSIS In those cases in which the illness is $\tilde{O}^{\circ}$ labelled 'psychiatric', a change of label to $\mathrm{W}$ 'organic' is impeded by 'diagnostic inertia'. 
Gauron and Dickinson (1969), in a study of diagnostic decision making, found this form of inertia to be an important factor delaying arrival at a correct diagnosis. In the situation we have studied, diagnostic inertia results from referral of the patient to a psychiatric hospital, since, although the referral is made largely because of management difficulties, a psychiatric reason is then sought to justify the referral. Redlich et al. (1948) emphasized that, in the diagnosis of brain tumour, this tendency to cling to the first concept of the case is an important reason for delays and errors.

Diagnosis is further impeded by difficulties in obtaining a satisfactory history and physical examination. The patient may be incapable, uncooperative, or unreliable and may have lived in social isolation before admission. In this series neurological examination usually revealed some abnormality at the time of admission, but later neurological examination showed that some signs may have been missed, particularly visual field defects, ataxia on tandem gait, slight paresis, and abnormalities of parietal lobe function. Many of these patients developed further neurological signs with progress of their disease in the psychiatric hospital. Those patients noted in Table 1, column B, developed organic disease while inpatients, demonstrating that continuing review of psychiatric inpatients is clearly necessary.

The high frequency of abnormalities discovered in the electroencephalogram, radiographs of the skull and chest, and lumbar puncture is noteworthy. Electroencephalography and radiology are of course relatively harmless procedures but lumbar puncture in the presence of increased intracranial pressure is not (Duffy, 1969). In this series three patients deteriorated after lumbar puncture. Cerebral scans were performed in a few cases only, because of practical difficulties, but this investigation undoubtedly is useful as well as being relatively simple and harmless.

The common diagnostic problems in this series were:

1. The differentiation of dementia and psychotic illness, especially depression.

2. The separation of irremediable-for example, degenerative-causes of dementia from causes which may in some cases respond to treatment-for example, meningiomas, normal pressure hydrocephalus.

3. The separation of neurosurgical causes of acute confusional states in an alcohol or drug dependent patient from the more usual causesthat is, drug intoxication and withdrawal.

4. The presence of apparently sufficient social and psychiatric factors to produce a postulated psychiatric disease.

PATTERN OF DISEASE A feature of the series is the high incidence of subdural haematomas and subarachnoid haemorrhage and the low incidence of meningiomas. The high incidence of subdural haematomas is related to the prevalence of alcoholism in the community and to the tendency to refer such patients to psychiatric hospitals. Selecki (1965) also noted this high incidence in a similar series investigated at the PRU.

The unexpectedly high incidence of subarachnoid haemorrhage would seem to have been the result of the associated mental symptoms. Walton (1956) described confusion as a presenting feature of subarachnoid haemorrhage in $4 \%$ of cases. Three of his 275 patients were accused of drunkenness, and one was arrested. Two were thought to have been hysterical when first seen in hospital. Others had 'protean' mental abnormalities including violence and were described as confabulating, whining, and uncooperative. In 576 cases of subarachnoid haemorrhage, Heidrich (1966) found cases of delirium, twilight states, Korsakov's psychosis, and schizophrenic-like pictures. Despite this, the relatively common psychiatric presentation of subarachnoid haemorrhage has not been adequately recognized.

From the postmortem reviews and clinical studies already mentioned, a high incidence of meningiomas could be expected. Patton and Sheppard (1956) found that $32 \%$ of intracranial tumours in psychiatric patients were meningiomas. The low incidence in this series however corresponds with that found by Selecki (1965).

HARM OR BENEFIT? Delayed diagnosis was apparent in a number of cases and it may be claimed that the delay was a consequence of the patients being sent to a psychiatric hospital. 
However, most of these patients could not have been managed in general hospitals, since general hospital staff are not at present equipped by training or attitude to cope with people who are mentally abnormal, rowdy, disruptive, and socially unacceptable.

Adequate management within the psychiatric hospitals is possible provided that full neurological and neurosurgical facilities are available and the staff is suitably trained and oriented. The standard of physical care must be equal to that available at general hospitals, associated with an equally high standard of psychiatric care.

We are grateful to Professor L. G. Kiloh for his assistance and to Dr. W. A. Barclay, Director of State Psychiatric Services, for permission to publish the findings.

\section{REFERENCES}

Allen, A. M., Moore, M., and Daly, B. B. (1940). Subdural hemorrhage in patients with mental disease. A statistical study. New England Journal of Medicine, 223, 324-329.

Bleuler, M. (1951). Psychiatry of cerebral diseases. British Medical Journal, 2, 1233-1237.

Briscoe, O. V. (1968). The meaning of 'mentally ill person' in the Mental Health Act, 1958-1965 of New South Wales. Australian Law Journal, 42, 207-215.

Dinnen, A., Gye, R., and Bell, D. Mental disturbances associated with craniopharyngioma in adults. Medical Journal of Australia, 1, 735-737.

Duffy, G. P. (1969). Lumbar puncture in the presence of raised intracranial pressure. British Medical Journal, 1, 407-409.

Gauron, E. F., and Dickinson, J. K. (1969). The influence of seeing the patient first on diagnostic decision making in psychiatry. American Journal of Psychiatry, 126, 199-205.

Gooddy, W., Gautier-Smith, P. C., and Dunkley, E. W. (1960). Neurological practice in a mental observation unit. Lancet, 2, 1290-1292.

Heidrich, R. (1966). Die psychischen Störungen der Subarachnoidealblutung. Wiener Zeitschrift für Nervenheilkunde und deren Grenzgebiete, 23, 316-326.

Hobbs, G. E. (1965). Brain tumours simulating psychiatric disease. Canadian Medical Association Journal, 88, 186-188.

Klotz, M. (1957). Incidence of brain tumors in patients hospitalized for chronic mental disorders. Psychiatric Quarterly, 31, 669-680.

Larson, C. P. (1940). Intracranial tumors in mental hospital patients. A statistical study. American Journal of Psychiatry, 97, 49-54.

Olin, H. S., and Weisman, A. D. (1964). Psychiatric misdiagnosis in early neurological disease. Journal of the American Medical Association, 189, 533-538.

Patton, R. B., and Sheppard, J. A. (1956). Intracranial $\vec{O}$ tumors found at autopsy in mental patients. American Journal of Psychiatry, 113, 319-324.

Pihkanen, T. A., and Vauhkonen, M.-L. (1967). Haematoma subdurale in the patient material of a neuropsychiatric hospital. (Abstract.) Acta Neurologica Scandinavica, 43, Suppl. 31, 190.

Redlich, F. C., Dunsmore, R. H., and Brody, E. B. (1948), . Delays and errors in the diagnosis of brain tumor. Ne+t. England Journal of Medicine, 239, 945-950.

Rubert, S. L., and Remington, F. B. (1963). Why patien $\vec{N}$ with brain tumors come to a psychiatric hospital: a 30-ye皮 윽 survey. Psychiatric Quarterly, 37, 253-263.

Selecki, B. R. (1965). Intracranial space-occupying lesionf among patients admitted to mental hospitals. Medicat Journal of Australia, 1, 383-390.

Victor, M., and Adams, R. D. (1966). Derangements intellect and behavior including delirium and other confitz. sional states, Ko̊rsakoff's amnestic syndrome and demefs tia. In Principles of Internal Medicine, 5th edn, pp. 264 280. Edited by T. R. Harrison, R. D. Adams, I. L. Bennett, W. H. Resnik, G. W. Thorn, and M. M. Wintrobe. McGraw-Hill: New York.

Walton, J. N. (1956). Subarachnoid Haemorrhage. Livingstone: Edinburgh. 